DE

M E D I C I N A

T R O P I C A L

$\mathrm{DE}$

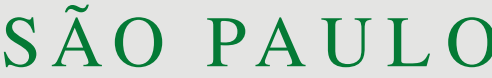

JOURNAL OF THE SÃO PAULO INSTITUTE OF TROPICAL MEDICINE

1Universidade Federal do Maranhão, Programa de Pós-Graduação em Saúde do Adulto, São Luís, Maranhão, Brazil

2Universidade Ceuma, Curso de Enfermagem, São Luís, Maranhão, Brazil

${ }^{3}$ Universidade Estadual de Campinas, Programa de Pós-Graduação em Clínica Médica, Campinas, São Paulo, Brazil

${ }^{4}$ Universidade Ceuma, Programa de PósGraduação em Biologia Parasitária, São Luís, Maranhão, Brazil

Correspondence to: Maria do Desterro Soares Brandão Nascimento Universidade Federal do Maranhão, Programa de Pós-Graduação em Saúde do Adulto, Avenida dos Portugueses, 1966, Bacanga, CEP 65080-805, São Luís, MA, Brazil

Tel: +55 $983272-8535$

E-mail: cnsd_ma@uol.com.br

Received: 13 July 2018

Accepted: 13 September 2018

\section{Adhesion and biofilm formation of Candida parapsilosis isolated from vaginal secretions to copper intrauterine devices}

\author{
Katia Regina Assunção Borges ${ }^{1}$, Igor Vinícius Pimentel1, Lidiane Cristina \\ Lima dos Santos Lucena², Marcos Antonio Custódio Neto da Silva ${ }^{3}$, Silvio \\ Gomes Monteiro ${ }^{4}$, Cristina Andrade Monteiro ${ }^{4}$, Maria do Desterro Soares \\ Brandão Nascimento', Geusa Felipa de Barros Bezerra ${ }^{1}$
}

\section{ABSTRACT}

Introduction: Candida parapsilosis is one of the main species that is able to adhere to forming biofilms on inert materials. Adhesion is the first step towards the colonization and invasion of host cells during the infectious process. Among the infections, vulvovaginal candidiasis is increasingly common. The objective was to evaluate the profile of adherence and biofilm formation of eight isolates of $C$. parapsilosis on the metal used in intrauterine devices (IUDs). Methods: Eight strains of $C$. parapsilosis presenting strong adhesion and biofilm formation properties were isolated from vaginal secretions in a previous study. To assay the adhesion and biofilm formation, copper fragments were made and cultivated in tubes containing $3 \mathrm{~mL}$ of phosphate-buffered saline and incubated for 6 and $24 \mathrm{~h}$ at $37^{\circ} \mathrm{C}$ to evaluate biofilm formation. After incubation, the intensity of adherence and of biofilm formation on copper fragments were determined by performing a colony count. Results: All isolates were able to form biofilms and the isolate Cp62 showed many cells joined in a planktonic mode forming biofilms. The use of an IUD is one of the main factors that favors vulvovaginal candidiasis, and the presence of copper in this device increases the chance of recurrent vulvovaginal candidiasis (CVVR) due to the ease with which species of the genus Candida can adhere to inert surfaces. Conclusion: This research showed that the clinical isolates studied adhered to IUD copper fragments and formed biofilms, further increasing their virulence.

KEYWORDS: Candida parapsilosis. Adhesion property. Formation of biofilm.

\section{INTRODUCTION}

The normal vaginal microbiota is predominantly comprised of lactobacilli (bacilli Döderlein hosting), which promote the proper acidity of the vaginal environment $(\sim$ pH 4.5); this hinders the proliferation of most microorganisms that can eventually be pathogenic. Despite this balance, several factors contribute to the colonization of vagina by Candida species, sometimes favoring the onset of symptoms or the occurrence of asymptomatic infections ${ }^{1,2}$.

It is estimated that vulvovaginal candidiasis (VVC) is the second most frequent cause of vaginal symptoms, representing 17 to $39 \%$ of the cases, and bacterial vaginosis (BV) corresponding to about $50 \%^{2}$. Around $75 \%$ of women present with vaginal discomfort at any stage of life, and among these cases, 50\% have other episodes of VVC and 5\% have recurrent vulvovaginal candidiasis (CVVR). This medical condition is caused by a single agent, but the mechanism going 
from transformation to colonization and to infection is multifactorial $^{3}$.

Candida parapsilosis is the second most common species isolated in different types of candidiasis ${ }^{4-6}$. The frequency is $15.5 \%$ in North America, $23.4 \%$ in Europe, and $16.3 \%$ in Latin America. In the United States, VVC is caused by the Candida species albicans and is not related to the widespread use of oral antifungals. In a study of 211 women in India with suspected VVC, 50 cases were confirmed by culture of vaginal secretions $(23.7 \%)$. The identified species were C. glabrata $(45.1 \%)$, followed by C. tropicalis (23.5\%), C. albicans (17.6\%), C. krusei $(9.8 \%)$ and $C$. parapsilosis $(3.9 \%)$. In addition, there was no association between $C$. glabrata and C. albicans in $2 \%$ and $0.5 \%$ of the positive cultures from the cases of $\mathrm{VVC}^{7}$.

In general, C. albicans is responsible for 85 to $90 \%$ of cases, followed by C. glabrata, C. tropicalis, C. krusei, and C. parapsilopsis; moreover, C. albicans is associated with coinfections and recurrent or chronic cases of the disease. In women with VVC, clinical manifestations vary from asymptomatic colonization to a severe, symptomatic acute infection $^{8,9}$.

Recurring causes are related to the symptomatic stage along with the vaginal microbiota and the predisposing factors that define the host susceptibility through interference with the population of lactobacilli, such as the use of antibiotics, reducing the population of Lactobacillus acidophilus; the use of spermicide; the use of oral contraceptives and antifungals without prescription medications ${ }^{10,11}$, and other factors such as an increase in temperature, changes in the humidity, and local mucosal trauma, caused by the use of excessively tight clothing and underwear, especially the ones made with synthetic fibers. All of these factors can lead to the development of candidiasis $^{3}$.

A factor that can facilitate the colonization of Candida is the use of intrauterine devices (IUDs), which can intensify the woman's susceptibility for vaginosis due to virulence factors of the Candida species $^{12-15}$. Several studies have shown that Candida species can easily adhere to and form biofilms on inert surfaces, such as glass, metals, silicon, plastics, and acrylics ${ }^{16,17}$.

The ability of accession is the first step in developing VVC. In this mechanism, proteins called adhesins mediate the recognition and binding of fungal cells to cells and to inert surfaces ${ }^{18}$. Additionally, formation of a biofilm is intrinsically favored by the accession process, as well as by the association with microbial cells, which is characterized by a specific gene expression pattern ${ }^{19-21}$. This process occurs at different stages including the initial adhesion and colonization that is followed by cell division, proliferation, and the biofilm maturation, which can include yeast forms and filaments that are suitable for the colonization of inert surfaces.

Thus, the objective of this study was to evaluate the intensity of the adherence and the biofilm formation of C. parapsilosis on copper that is present in IUDS.

\section{METHODS}

The study was descriptive with experimental and prospective characteristics that covered quantitative analysis of data. For the experiments, eight isolates of C. parapsilosis (vaginal secretion) were used. They were kindly provided by the laboratory of endemic and parasitic diseases of Ceuma University.

From the isolates, a standard solution was prepared from the 24-h colonies that were grown in Sabouraud dextrose medium (SDA) with chloramphenicol (Acumedia). After this period, they were resuspended in a $0.85 \%$ saline solution and standardized to approximately $10^{6} \mathrm{CFU} / \mathrm{mL}$, in accordance with a turbidity of 0.5 in a McFarland range tube (CLSI; Clinical and Laboratory Standards Institute, NCCLS, created in 2007) $)^{22}$.

To assay the adhesion and biofilms, copper fragments measuring $0.5 \mathrm{~mm}$ in diameter (made from model $\mathrm{TCu}$ 380A IUDs, adopted by the Ministry of Health for patients, based on SUS) were washed with sterile distilled water, and added to a tube containing $3 \mathrm{~mL}$ of PBS sterilized at $121^{\circ} \mathrm{C}$ in 1 x 15 min intervals.

Subsequently, $100 \mu \mathrm{L}$ of the fungal suspension was added to each tube containing the fragments for the two tests. They were incubated for 6 and $24 \mathrm{~h}$ to evaluate biofilm formation at $37^{\circ} \mathrm{C}$.

After the incubation period, each fragment was washed 3 times with sterile saline, carefully placed in tubes containing $3 \mathrm{~mL}$ of $0.85 \%$ saline solution and vortexed for $30 \mathrm{~s}$. From these samples, $100 \mu \mathrm{L}$ aliquots were added in duplicate to plates containing SDA middle, and the inoculants were spread using a Drigalski spatula. After $24 \mathrm{~h}$ of incubation, the number of colony forming units (CFUs) were determined for $0.1 \mathrm{~mL}$ of $C$. parapsilosis recovered from each fragment.

Adhesion and biofilm formation were classified by the material, according to the cell adhesion, which was considered to be negative for samples that did not show CFUs at the end of the process. Weak adhesion samples showed growth between 1 and 199 CFUs; moderate samples had CFUs between 200 and 499; strongly adhering samples had CFUs between 500 and 1,000 CFUs; and very strong adhesion samples had CFUs of more than 1,000 CFUs. 
Results were analyzed through the transcription of collected data to graphs and tables.

\section{RESULTS}

\section{Adhesion test}

The eight isolates of $C$. parapsilosis used in this study were able to adhere to copper, as shown in chart 1 , and a discrete difference in the number of attached cells was observed. Of note, isolate $\mathrm{Cp} 9$ adhered more to the copper fragment compared to other isolates, with CFUs of $\mathrm{x} 18.25 \times 10^{2}$ (Figure 1).

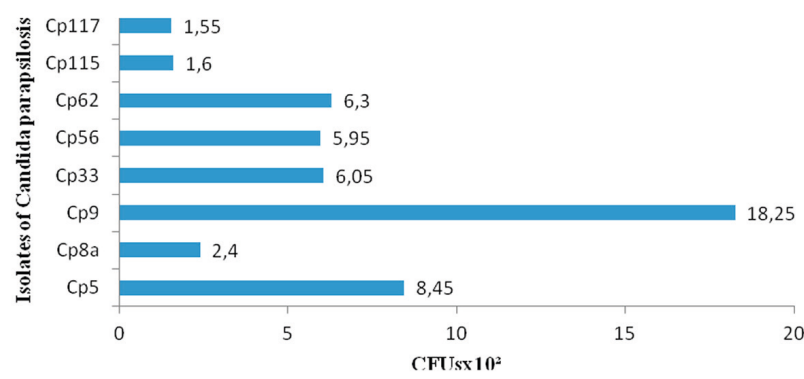

Figure 1 - Distribution of the number of CFUs isolates adhered to copper

Regarding the grip strength (Table 1), we noted that seven of the isolates (Cp5, Cp8A, Cp33, Cp56, Cp62, $\mathrm{Cp} 115$, and Cp117) had weak intensities, and one isolate (Cp9) had a moderate intensity.

Table 1 - Distribution of the adherence intensity of Candida parapsilosis isolates to copper

\begin{tabular}{cc}
\hline Isolates & Intensity adherence \\
\hline$C p 5$ & Weak \\
$C p 8 \mathrm{~A}$ & Weak \\
Cp9 & Mild \\
$C p 33$ & Weak \\
$C p 56$ & Weak \\
$C p 62$ & Weak \\
$C p 115$ & Weak \\
$C p 117$ & Weak \\
\hline
\end{tabular}

\section{Biofilm assay}

Our results showed that the eight isolates of $C$. parapsilosis formed biofilms on copper. Among these, isolate Cp62 showed the highest number of cells in the biofilm (36.45 x $\left.10^{2} \mathrm{CFUs}\right)$, followed by isolates Cp56 (33.6 x $10^{2}$ CFUs) and Cp33 (22.2 x 102 CFUs). For the other isolates, we observed 1.7, 21.1, 18.1, 4.45, and $14.9 \times 10^{2}$ CFUs for Cp5, Cp8A, Cp9, Cp115, and Cp117, respectively, for formation of a biofilm on copper (Figure 2).

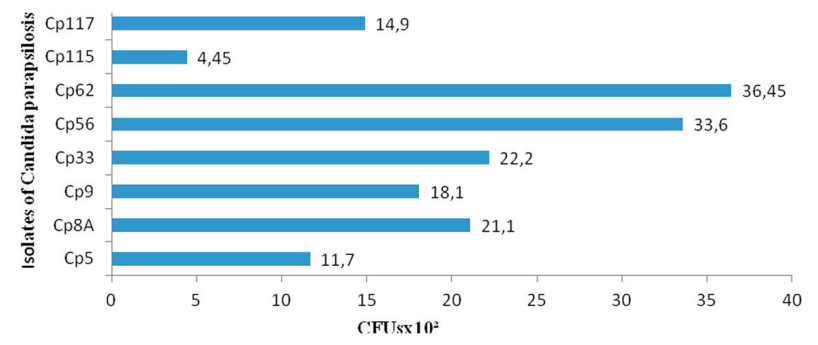

Figure 2 - Distribution of the number of cells per CFUs $\times 10^{2}$ in the formation of biofilm isolates of $C$. parapsilosis

Regarding the intensity of biofilm, after calculating the estimated number of cells that remained attached for $24 \mathrm{~h}$, which are suggestive of biofilm, the number of cells indicated a weak profile biofilms (Table 2).

Table 2 - Distribution of the number of cells and biofilm intensity to copper

\begin{tabular}{ccc}
\hline Isolates & CFu & Intensity to copper \\
\hline Cp5 & 11,7 & Weak \\
Cp8A & 21,1 & Weak \\
Cp9 & 18,1 & Weak \\
Cp33 & 22,2 & Weak \\
Cp56 & 33,6 & Weak \\
Cp62 & 36,45 & Weak \\
Cp115 & 4,45 & Weak \\
Cp117 & 14,9 & Weak \\
\hline
\end{tabular}

\section{DISCUSSION}

The ability to adhere to surfaces with different intensities can be related to the fact that $C$. parapsilosis consists of three different, closely related complexes. The genetic characteristics allow their separation and classification as C. parapsilosis, C. orthopsilosis, and C. metapsilosis ${ }^{23}$.

Studies claim that $C$. parapsilosis has high adhesion to biomaterials due to the ease with which it adheres to various types of surfaces such as plastic, glass, central venous catheters, urinary catheters and other dispositives used in situations where there is a need for prolonged or permanent access. Additionally, as the use of IUDs increases, the chance of colonization by these isolates increases, as does the persistence of $\mathrm{CVV}^{24}$.

As already known, a biofilm is a complex layer of cells that is associated with areas that together form an array, giving the organism protection from the host's defenses, as 
well as antifungal activity and several species of Candida, mainly C. parapsilosis, forming biofilms on different inert surfaces, like the IUD ${ }^{11}$. In our study, the biofilm had a weak intensity after $24 \mathrm{~h}$; however, an IUD remains inserted in the intrauterine cavity for a long period of time and this result suggests that it can contribute to VVC recurrence.

In a similar study using central venous catheters, Titton et al. ${ }^{17}$ analyzed the formation of biofilms by C. albicans, C. tropicalis, and C. parapsilosis and compared the results between species, and they found that $C$. parapsilosis showed the highest rate of colonization, compared to C. albicans and $C$. tropicalis, after 24 and $48 \mathrm{~h}$ of incubation.

Corroborating our work, Segal et al..$^{12}$ and Auler et al. ${ }^{14}$ studied the formation of biofilms in IUD and reported that women who use IUDs are susceptible to episodes of CVV, especially at the insertion site because all devices studied presented with Candida spp. biofilms.

\section{CONCLUSION}

Results of this research show that the clinical isolates studied are able to adhere to the copper of IUDs and form biofilms, further increasing their virulence. In this way, these results imply a high pathogenicity for the virulence factors of this species, and it may have a significant role in the use of copper IUD.

\section{REFERENCES}

1. Etgeton SA, Chassot F, Boer CG, Donatti L, Svidzinski TI, Consolaro ME. Influência da co-agregação entre Candida albicans e Lactobacillus acidophilus na capacidade de adesão destes microrganismos às células epiteliais vaginais humanas (CEVH). Acta Sci. Health Sci. 2011;33:1-8.

2. Nomelini RS, Carrijo AP, Adad SJ, Nunes AA, Murta EF. Relationship between infectious agents for vulvovaginitis and skin color. Sao Paulo Med J. 2010;128:348-53.

3. Feuerschuette OH, Silveira SK, Feuerschuette I, Correa T, Grando L, Trepani A. Candídiase vaginal recorrente: manejo clínico. FEMINA. 2010;38:31-6.

4. Ferrazza MH, Maluf ML, Consolaro ME, Shinobu CS, Svidzinski TI, Batista MR. Caracterização de leveduras isoladas da vagina e sua associação com candidíase vulvovaginal em duas cidades do sul do Brasil. Rev Bras Ginecol Obstet. 2005;27:58-63.

5. Trofa D, Gácser A, Nosanchuk JD. Candida parapsilosis: an emerging fungal pathogen. Clin Microbiol Rev. 2008;21:60625 .

6. Menezes VM, Vale IN, Monteiro SG, Gonçalves LH, Figueiredo PM, Monteiro CA. Classificação da capacidade de adesão de isolados clínicos de Candida spp em padrões de arranjos celulares distintos. Rev Patol Trop. 2013;42:289-300.
7. Kalaiarasan K, Singh R, Chaturvedula L. Fungal profile of vulvovagnal candidiasis in a tertiary care hospital. J Clin Diagn Res. 2017;11:DC06-9.

8. Heng LZ, Chen Y, Tan TC. Treatment of recurrent vulvo-vaginal candidiasis with sustained-release butoconazole pessary. Singapore Med J. 2012;53:e269-71.

9. Tozzo AB, Grazziotin NA. Candidíase vulvovaginal. Perspectiva. 2012;3:53-62.

10. Eschenbach DA. Vaginal infection. Clin Obstet Gynecol. 1983;26:186-202.

11. Shimp LA. Vaginal and vulvovaginal disorders. In: Berard RR, Desimone EM, Newton GD, Oszko MA, Pagovitch NG, Rollins CJ, et al., editors Handbook of nonprescription drugs. $13^{\text {th }}$ ed. Washington: American Pharmaceutical Association; 2002. p.129-47.

12. Segal D, Gohar J, Huleihel M, Mazor M. Fetal death associated with asymptomatic intrauterine Candida albicans infection and a retained intrauterine contraceptive device. Scand J Infect Dis. 2001;33:77-8

13. Kuhn DM, Chandra J, Mukherjee PK, Ghannoum MA. Comparison of biofilms formed by Candida albicans and Candida parapsilosis on bioprosthetic surfaces. Infect Immun. 2002;70:878-88.

14. Auler ME, Morreira D, Rodrigues FF, Abr Ao MS, Margarido PF, Matsumoto FE, et al. Biofilm formation on intrauterine devices in patients with recurrent vulvovaginal candidiasis. Med Mycol. 2010;48:211-6.

15. Nosek J, Tomáska L, Rycovská A, Fukuhara H. Mitochondrial telomeres as molecular markers for identification of the opportunistic yeast pathogen Candida parapsilosis. J Clin Microbiol. 2002;40:1283-9.

16. Silva S, Negri M, Henriques M, Oliveira R, Williams DW, Azeredo J. Candida glabrata, Candida parapsilosis and Candida tropicalis: biology, epidemiology, phatogenecity and antifungal resistence. FEMS Microbiol Rev. 2012;36:288-305.

17. Titton EC, Belo RA, Siqueira FS, Silva G, Khouri S. Avaliação de biofilme de candida spp em cateter venoso central por cultura quantitativa e microscopia eletrônica de varredura. In: XII Encontro Latino Americano de Iniciação Científica, VIII Encontro Latino Americano de Pós-Graduação; 2008 Oct 1617; São José dos Campos, Brasil.

18. Li F, Svarovsky MJ, Karlsson AJ, Wagner JP, Marchillo K, Oshel P, et al. Eap1p, an adhesin that mediates Candida albicans biofilm formation in vitro and in vivo. Eukaryot Cell. 2007;6:931-9.

19. Shin JH, Kee SJ, Shin MG, Kim SH, Shin DH, Lee SK, et al. Biofilm production by isolates of Candida species recovered from nonneutropenic patients: comparison of bloodstream isolates with isolates from others sources. J Clin Microbiol. 2002;40:1244-8.

20. Pires RH, Santos JM, Zaia JE, Martins CH, Mendes-Giannini MJ. Candida parapsilosis complex water isolates from a 
haemodialysis unit: biofilm production and in vitro evaluation of the use of clinical antifungals. Mem Inst Oswaldo Cruz. 2011;106:646-54.

21. Jabra-Rizk MA, Falkler WA Jr, Merz WG, Baqui AA, Kelley JI, Meiller TF. Cell surface hydrophobicity associated adherence of Candida dubliniensis to human buccal epithelial cells. Rev Iberoam Micol. 2001;18:17-22.

22. Clinical and Laboratory Standards Institute. Methods for dilution antimicrobial susceptibility tests for bacteria that grow aerobically; approved standard - $9^{\text {th }}$ ed. Wayne: CLSI; 2012.
23. Tavanti A, Gow NA, Senesi S, Maiden MC, Odds FC. Optimization and validation of multilocus sequence typing for Candida albicans. J Clin Microbiol. 2003;41:3765-76.

24. Dagdeviren M, Cerikcioglu N, Karavus M. Acid proteinase, phospholipase and adherence properties of Candida parapsilosis strains isolated from clinical specimens of hospitalised patients. Mycoses. 2005;48:321-6. 